\title{
Price competition between two international firms facing tariffs
}

\author{
Eric O'N. Fisher ${ }^{\mathrm{a}}$, Charles A. Wilson ${ }^{\mathrm{b}}$ \\ ${ }^{a}$ Department of Economics, The Ohio State University, 410 Arps Hall, \\ 1945 North High Street, Columbus, OH 43210, USA \\ 'Department of Economics, New York University, 269 Mercer Street, 7th Floor, New York, \\ NY 10003, USA
}

\begin{abstract}
This paper examines the effects of tariffs on price-setting duopolists selling a homogeneous product. The producers cannot segment geographically distinct markets. It provides a complete characterization of the equilibrium (mixed) strategies and analyzes the pattern of competition for different tariffs. If a country raises its tariff, the profits of both producers increase, although the protected firm typically benefits more than its foreign counterpart. Growth in one market may reduce the profits of the firm located in the other market.
\end{abstract}

Keywords: Commercial policy; Imperfect competition; Anti-dumping

\section{Introduction}

This paper analyzes the effects of tariffs on an international market where two firms sell a homogeneous good. Each firm produces at zero marginal cost, and the domestic market of at least one firm is protected by a tariff. We emphasize two points: first, commercial policy in one market may have an 
influence in all national markets; and second, there is a limit to market segmentation when the goods sold in different countries are close substitutes.

If there is no tariff, this analysis reduces to the standard Bertrand model without capacity constraints. Then the only equilibrium is for both firms to price at marginal cost. Even with tariffs, a similar result obtains if market segmentation is permitted: competition drives the price in each country down to its tariff. ${ }^{1}$ We concentrate on the case without market segmentation; each firm must set only one price for both exports and domestic sales. This is equivalent to assuming that neither firm can dump its product. ${ }^{2}$ A protected firm can benefit from a tariff only by charging a positive price for all sales. This permits the other firm to raise its price and make positive expected profits in its own market.

Because the profit functions are discontinuous, equilibria in pure strategies may not exist. ${ }^{3}$ However, under reasonably general assumptions, we characterize a unique mixed strategy equilibrium for each pair of tariffs. Think of each pure strategy as a price representing a marketing choice. Then a firm chooses a mix of aggressive and conservative prices. Aggressive prices are low enough to capture the home market with certainty, and to capture the foreign market with positive probability. Conservative prices preclude capturing the foreign market, but they assure higher expected profits in the home market.

If the tariffs in both countries are sufficiently low, both firms randomize using a range of aggressive and conservative prices. As the tariffs rise, the average prices charged by the firms also increase. For high enough tariffs, both firms concentrate on conservative prices, and the markets are effectively segmented. When only one country imposes a high tariff, the structure of the equilibrium becomes very asymmetric, and the heavily protected firm mixes conservative and aggressive prices. The poorly protected firm also randomizes, charging conservative prices in order to sell above cost in its

\footnotetext{
${ }^{1}$ One can interpret these tariffs as transportation costs or compensating differentials for consumers with discretely different most preferred brands. Eaton and Engers (1990) and Baye and de Vries (1992) discuss this point. Also, almost all the literature on oligopoly in international economics has used the assumption of market segmentation, not to model empirical aspects of international trade, but because this assumption makes these kinds of models analytically tractable. We are an important exception to this tradition.

${ }^{2}$ In the Trade Agreement Act of 1979 , the United States defines dumping as charging an export price that is less than fair market value and that is likely to result in injury to a domestic industry. Fair market value is: (1) the price in the exporter's own market; (2) the price in a third market; or (3) the Department of Commerce's estimate of average cost plus a markup for 'reasonable' profits. In practice, tariffs are imposed according to country of origin; hence, competition among importers with access to several national markets will entail that firms charge one price for sales in the world market.

${ }^{3}$ See Dasgupta and Maskin $(1986 a, b)$ for a systematic treatment of this issue.
} 
own domestic market. But a high tariff makes it impossible for the poorly protected firm to be aggressive since such a tariff effectively prohibits it from exporting.

The paper is structured as follows. Section 2 contains a brief survey of the literature. Sections 3 and 4 provide a systematic derivation of the equilibrium. Section 5 analyzes comparative statics. It shows that an increase in the tariff rate of one country must increase the profits of both firms. It also examines the implications of a change in the size of the market of one country and present two simple examples. Then we give a brief conclusion.

\section{Some related literature}

On a technical level, our analysis is related to the work of Levitan and Shubik (1972), who characterize the mixed strategy in an EdgeworthBertrand duopoly. It is even more closely related to a paper by Shilony (1977) addressing how oligopolists set prices in a simple location model; he characterizes the equilibrium when demand is completely inelastic and countries and tariff rates are symmetric. Varian (1980) investigates the role of information on the equilibrium pricing strategies.

The literature on brand loyalty is also closely related to our model. Narasimhan (1988) analyzes product loyalty in a model where undercutting one's rival by a discrete amount induces consumers to switch to a new brand. Farrell and Shapiro (1988) analyze a model of overlapping generations where incumbent firms have loyal customers and entrants price aggressively in order to build up a base of future loyal customers. Raju et al. (1990) analyze Bertrand equilibria in games with various asymmetric forms of brand loyalty.

This paper is a major extension of these two strands of literature. Previous work uses the fact that each firm's profits are tied down by some idiosyncratic brand loyalty or informational asymmetry. Once a firm's equilibrium level of profits is known, it is then possible to determine the mixed strategy equilibrium. In our model, one cannot determine one firm's profits independently of those of the other firm. All of our arguments lead to a simultaneous determination of the equilibrium profits of both firms, making for a much more difficult problem than has been solved previously. Also, we allow for more general classes of demand functions and asymmetries. Hence, the earlier analyses cannot be applied in a straightforward manner.

It is only in recent years that economists have investigated market structure and international trade in explicitly game-theoretic models. Brander (1981) shows that transport costs give rise to two-way trade if duopolists segment markets and choose separate quantities for domestic and foreign 
sales. Helpman (1984) discusses the importance of the assumption of segmented markets in models of international oligopoly. Analyzing only one market, Krishna (1989) shows that quotas placed on one firm in a Bertrand duopoly can benefit both firms. Bulow et al. (1985) emphasize the strategic interdependence of producers acting in distinct markets. They show that shocks affecting a firm's profitability in one market influence its best response and hence the profits of its competitors in other markets. Eaton and Engers (1990) examine a dynamic version of a special case of our model where demand is perfectly inelastic. Assuming that firms set prices in alternate periods, they characterize the Markov-perfect equilibria for that game. Baye and de Vries (1992) examine a model of international trade and solve for an equilibrium in mixed strategies when some of the consumers have brand loyalty and others do not. An extensive bibliography of gametheoretic issues in international trade theory is given by McMillan (1986).

\section{The model}

There are two firms producing a homogeneous good at zero marginal cost. Firm 1 is located in country 1 , and firm 2 is located in country 2 . In country $i$, there is a non-negative specific tariff, $t_{i}$, on the good produced in the other country. The demand per consumer at any positive price $p$ is $D(p)$ in both countries. The countries may differ in size, with $k_{i}$ consumers in country $i$.

Firms simultaneously choose (non-negative) prices. Thus, if firm $i$ charges price $p$, it sells its output at $p$ in country $i$ but at $p+t_{j}$ in country $j$. The firm with the lowest after-tariff price in any country captures that market. If both firms charge the same price in some market, then they split the market equally. ${ }^{4}$

For $p \geqslant 0$, let $k_{i} \pi(p) \equiv k_{i} p D(p)$ be the profit earned by firm $i$ in its domestic market when it charges the lowest after-tariff price there. Let $k_{j} \pi_{i}^{*}(p) \equiv k_{j} p D\left(p+t_{j}\right)$ be the profit earned by firm $i$ in the foreign market when it charges the lowest after-tariff price there. We assume that

Assumption 1. (a) $\pi(0) \equiv \lim _{p \downarrow 0} \pi(p)=0$; (b) $\pi(\cdot)$ attains a unique maximum at $p_{m}$; and (c) $\pi(\cdot)$ is continuously differentiable and concave on $\left(0, p_{m}\right)$.

Assumption 1 implies that the marginal revenue of the domestic profit function is downward sloping on $\left[0, p_{m}\right]$. It also implies that the foreign profit function for firm $i$ is monotone on $\left[0, p_{m}-t_{j}\right]$.

In order to obtain a Nash equilibrium, it is necessary to permit firms to

${ }^{4}$ Our results are not sensitive with respect to the sharing rule. 
randomize their choices of $p$. Let $G_{i}(p)$ be the decumulative distribution function of the price charged by firm $i$; this function may not be continuous. $G_{i}(p)$ is the probability that firm $i$ charges a price greater than or equal to $p$. Let $q_{i}(p)$ denote the probability mass of $G_{i}(\cdot)$ at price $p$. Then

$$
\begin{aligned}
\Pi_{i}\left(p, G_{j}\right)= & {\left[G_{j}\left(p-t_{i}\right)-q_{j}\left(p-t_{i}\right) / 2\right] k_{i} \pi(p) } \\
& +\left[G_{j}\left(p+t_{j}\right)-q_{j}\left(p+t_{j}\right) / 2\right] k_{j} \pi_{i}^{*}(p)
\end{aligned}
$$

is the expected profit to firm $i$ from selling at price $p$ when the foreign firm follows strategy $G_{j}$. The term $G_{i}\left(p-t_{i}\right)$ is the probability that firm $i$ makes import-competing sales at home, and $q_{j}\left(p-t_{i}\right) / 2$ reflects the assumption that the firms split market $i$ if firm $j$ charges $p-t_{i}$. Likewise, $G_{j}\left(p+t_{j}\right)$ is the probability that firm $i$ makes export sales, and $q_{j}\left(p+t_{j}\right) / 2$ is the probability that both firms sell in market $j$. Although the expected profits of firm $i$ may not be continuous in $p$,

$$
\lim _{\delta \downarrow 0} \Pi_{i}\left(p-\delta, G_{j}\right) \geqslant \Pi_{i}\left(p, G_{j}\right) \geqslant \lim _{\delta \downarrow 0} \Pi_{i}\left(p+\delta, G_{j}\right)
$$

for $p \in\left[0, p_{m}\right]$ because undercutting firm $j$ causes a discrete increase in firm $i$ 's expected profits if firm $j$ charges $p-t_{i}$ or $p+t_{j}$ with strictly positive probability.

Let $v_{i}=\sup _{p \geqslant 0} \Pi_{i}\left(p, G_{j}\right)$ be the highest expected profit attainable by firm $i$, given that the form $j$ follows strategy $G_{j}$. Then a pair of strategies $\left(G_{1}, G_{2}\right)$ is an equilibrium if

$$
\int \Pi_{1}\left(p, G_{2}\right) \mathrm{d} G_{1}=v_{1} \text { and } \int \Pi_{2}\left(p, G_{1}\right) \mathrm{d} G_{2}=v_{2} .
$$

Each firm's strategy is optimal since, at any price it charges, its expected profits are as high as possible, taking the other firm's strategy as given.

\section{Derivation of equilibrium}

In this section, we establish a series of results which lead to a characterization of the unique equilibrium. For the remainder of the paper, $G_{1}$ and $G_{2}$ will refer to an equilibrium strategy pair, and $v_{1}$ and $v_{2}$ are expected equilibrium profits. Throughout this section, the tariffs are fixed at $t_{1}$ and $t_{2}$ and the market sizes are fixed at $k_{1}$ and $k_{2}$.

\subsection{Continuity of the equilibrium distributions of prices}

Although the imposition of a tariff complicates the analysis by creating two margins of competition at any price, standard arguments for Bertrand 
competition can still be used to establish the continuity of the equilibrium price distributions at any price below $p_{m}$. They also establish some relationships between the supports of the two distributions.

Note first that the imposition of a tariff by either country guarantees a positive expected profit for a protected firm. Hence, the support of the distribution of prices chosen by that firm must be bounded away from zero. This in turn guarantees a positive expected profit for the other firm. Therefore, we may state:

Lemma 1. If either $t_{1}>0$ or $t_{2}>0$, then $v_{1}>0$ and $v_{2}>0$.

Let $t \equiv t_{1}+t_{2}$ be the sum of the tariffs. From now on, we assume that at least one tariff is positive so that $t>0$. If firm $i$ is considering charging price $p \in\left[t, p_{m}\right]$, it can always undercut by charging $p-t$. Then it captures market $j$ with the same probability that it captured market $i$ at the original price. Hence, undercutting by $t$ changes a conservative price into an aggressive one. Since $t>0$, some firm may charge an aggressive price.

Given Lemma 1, we may also establish

Lemma 2. $q_{j}(p)>0$ implies $p=p_{m}$.

Proof. See the appendix.

Lemma 2 implies that the distribution of prices charged by either firm is continuous everywhere but perhaps at the monopoly price. Charging $p_{m}$ is quite conservative, but either firm may do so with strictly positive probability. Indeed, both firms will charge this price with certainty if both markets are perfectly protected.

Define $p_{i} \equiv \sup \left\{p: G_{i}(p)=1\right\}$ and $\bar{p}_{i}=\inf \left\{p: G_{i}(p)=0\right\}$. These are the lower and upper bounds of the support of the strategy $G_{i}$.

Lemma 3. (a) $G_{j}\left(\bar{p}_{i}-t_{i}\right)>0$; (b) $G_{j}\left(\bar{p}_{i}+t_{j}\right)=0$; (c) $\bar{p}_{i}-t_{i} \leqslant \bar{p}_{j} \leqslant p_{m}$; and (d) $\underline{p}_{i} \leqslant \underline{p}_{j}+t_{i}$.

Proof. See the appendix.

The proof of Lemma 3 uses the facts that the value of the game is positive for both firms and that the monopoly price is unique. Lemma 3 implies that the supports of the two distributions must overlap. Part (a) states that even an unprotected firm charges conservative prices with positive probability, and (b) implies that no firm charges a price so high that it loses its own market with certainty. Part (c) states that no firm charges a price above the monopoly price, and (d) shows that neither firm is so aggressive as to 
capture both markets with certainty. Since firms never charge prices outside $\left(0, p_{m}\right]$, any tariff greater than $p_{m}$ is prohibitive. Consequently, we assume that $t_{i} \leqslant p_{m}$. Lemma 3 states that a tariff anywhere in the world causes a firm to increase the profit rate in its own market, but no firm is completely aggressive in attacking a foreign market.

\subsection{Restrictions on the equilibrium ranges of prices}

Our next step is to determine bounds on the support of the price distributions. We begin by establishing an upper bound for $\bar{p}_{i}$.

Lemma 4. $\left[k_{j} /\left(k_{1}+k_{2}\right)\right] \bar{p}_{i} \leqslant t$.

Proof. See the appendix.

Lemma 4 states that firm $i$ will tend to be aggressive if market $j$ is large relative to market $i$. Indeed, the most conservative price a firm charges is that at the upper bound of the support of its strategy. Since firm $i$ could attack market $j$ by undercutting by $t$, charging $\bar{p}_{i}$ makes sense only if $k_{i} \bar{p}_{i} \geqslant\left(k_{1}+k_{2}\right)\left(\bar{p}_{i}-t\right)$. Lemma 4 also states that low tariffs imply that neither firm charges a very high price.

Using the assumption that $\underline{p}_{i}<\bar{p}_{i}-t$, we now establish a lower bound for $\bar{p}_{i}$,

Lemma 5. If $\underline{p}_{i}<\bar{p}_{i}-t$, then $\left[k_{i} /\left(k_{1}+k_{2}\right)\right] \bar{p}_{i}>t$.

Proof. See the appendix.

The hypothesis of Lemma 5 assumes that firm $i$ occasionally attacks firm $j$ by undercutting by $t$. The proof of Lemma 5 is accomplished in six steps, and it is quite difficult because we are dealing with fairly general demand functions. The first step establishes that if expected profits from domestic sales are increasing, then so are expected profits from foreign sales if a firm cuts price by $t$. The second step shows that if one firm undercuts by $t$, then so does the other firm. Hence, both firms occasionally attack if one does. The third step shows that an attacking firm will not charge prices in the middle of the support of the other firm's equilibrium strategy; indeed, if the supports of the equilibrium strategies are wide enough, these prices are neither aggressive nor conservative. The fourth step shows that a firm can then charge quite conservative prices since it need not worry about defending against foreign prices in the middle of its support. The fifth step shows that both firms occasionally charge the monopoly price, the highest individually rational pure strategy. Finally, the sixth step shows that a firm 
can charge this conservative price even if its own market is small. This contradiction establishes that no firm attacks by undercutting by more than $t$, the sum of the two tariffs.

Indeed, we are able to demonstrate a stronger property.

Lemma 6. $\bar{p}_{i}=\min \left\{\underline{p}_{i}+t, p_{m}\right\}$.

Proof. See the appendix.

Since firm $i$ charges prices in an interval no wider than $t$, Lemma 3(c) implies that $\vec{p}_{i}$ is less than or equal to the minimum of $\left\{\bar{p}_{i}+t, p_{m}\right\}$. If strict inequality holds, then $\bar{p}_{i}-t_{i}<\underline{p}_{i}+t_{j}$. So firm $j$ can charge prices above $\bar{p}_{i}-t_{i}$ and not worry about losing sales in its own market. But then firm $i$ can earn higher expected profits at some price $p>\bar{p}_{i}$ since it does not expect to capture market $j$ at such a high price and it need not worry about competition from firm $j$ at prices near $\bar{p}_{i}-t_{i}$. This contradicts the definition of the supremum of firm $i$ 's equilibrium strategy and establishes the equality in Lemma 6.

Lemma 6 shows that monopoly price will be the upper bound of the support of firm $i$ 's strategy if either tariff is high. Indeed, for small $t=t_{1}+t_{2}$ neither firm charges high prices, and it can be shown that both firms' equilibrium strategies are (perhaps different) connected intervals of width $t$. But if either $t_{1}$ or $t_{2}$ is large, then one firm is well protected, and it will charge $p_{m}$ with positive probability. Then the firms' equilibrium strategies may not be connected. Competition for the market of the poorly protected firm may occur, but there will be limits to how aggressive the protected firm will be. Finally, one can also show that

$$
G_{i}\left(\bar{p}_{j}-t_{j}\right)=G_{i}\left(\underline{p}_{j}+t_{i}\right),
$$

since prices in the interval $\left(\bar{p}_{j}-t_{j}, \underline{p}_{j}+t_{i}\right)$ are neither aggressive enough to attack the foreign market nor conservative enough to yield a high profit rate in one's own domestic market.

\subsection{Characterizing the equilibrium distributions of prices}

In this subsection we determine $v_{1}$ and $v_{2}$, the equilibrium level of expected profits for the two firms. Then we use $v_{j}$ to derive $G_{i}$ and show that there is a unique pair of equilibrium strategies.

\footnotetext{
${ }^{5}$ Let firm $i$ charge some price $\bar{p}_{j}-t_{j}<p<p_{j}+t_{i}$. Then its expected profits are $\Pi_{i}\left(p, G_{j}\right)=$ $k_{i} \pi(p)$, since it captures market $i$ with certainty and market $j$ with probability 0 . Since $\pi(p)$ is increasing on $\left[0, p_{m}\right]$, there is an $\varepsilon>0$ such that $\Pi_{i}\left(p+\varepsilon, G_{j}\right)=k_{i} \pi(p+\varepsilon)>k_{i} \pi(p)$; hence, charging price $p$ is not optimal.
} 
We do so by using an iterative procedure. First, fix $q_{i} \in[0,1]$ and $q_{j} \in[0,1]$. Then define the function $\phi_{i}:\left[0, p_{m}\right] \rightarrow \mathbb{R}_{+}$whose rule is

$$
\phi_{i}(p)=\left\{\begin{array}{ll}
k_{i} \pi(p)+q_{j} k_{j} \pi_{i}^{*}(p), & \text { if } 0 \leqslant p \leqslant p_{m}-t_{j}, \\
k_{i} \pi(p)+q_{j} k_{j} \pi_{i}^{*}\left(p_{m}-t_{j}\right), & \text { if } p_{m}-t_{j}<p \leqslant p_{m}
\end{array} .\right.
$$

If $p \leqslant p_{m}-t_{j}$, then $\phi_{i}(p)$ describes the expected profits firm $i$ earns from capturing its home market with certainty and the foreign market with probability $q_{j}$. If $p_{m}-t_{j}<p \leqslant p_{m}$, then $\phi_{i}(p)$ describes firm $i$ 's expected profits from capturing its own market with certainty at price $p$ and the foreign market with probability $q_{j}$ at the after-tariff price $p_{m}$. It is easy to check that $\phi_{i}(\cdot)$ is continuous and strictly increasing, and that $\phi_{i}(0)=0$. Hence, $\phi_{i}^{-1}(\cdot)$ exists and is also positive, continuous, and strictly increasing.

Now let $p_{1}^{(1)}=t_{1}, \quad v_{1}^{(1)}=k_{1} \pi\left(p_{1}^{(1)}\right), \quad p_{2}^{(1)}=\phi_{1}^{-1}\left(v_{1}^{(1)}\right)+t_{2}, \quad$ and $v_{2}^{(1)}=$ $k_{2} \pi\left(p_{2}^{(1)}\right)$. The value $v_{1}^{(1)}$ is what firm 1 can achieve simply by pricing at its tariff rate and capturing its own domestic market with certainty. Since firm 1 can assure itself $v_{1}^{(1)}$, its most aggressive price will be no lower than $\phi_{1}^{-1}\left(v_{1}^{(1)}\right)$. But then firm 2 can assure itself $v_{2}^{(1)}$ simply by charging $p_{2}^{(1)}=$ $\phi_{1}^{-1}\left(v_{1}^{(1)}\right)+t_{2}$ and capturing its own domestic market with certainty.

This insight allows one to define a sequence of values. In particular, for $n \geqslant 1, i \in\{1,2\}, j \in\{1,2\}$, and $i \neq j$, let

$$
p_{i}^{(n+1)}=\min \left\{\phi_{j}^{-1}\left(v_{j}^{(n)}\right)+t_{i}, p_{m}\right\} \quad \text { and } \quad v_{i}^{(n+1)}=k_{i} \pi\left(p_{i}^{(n+1)}\right) .
$$

Since both $\phi_{j}^{-1}(\cdot)$ and $\pi(\cdot)$ are increasing, $\left\{v_{i}^{(n+1)}\right\}_{n=1}^{\infty}$ is a non-decreasing sequence of positive numbers bounded from above by $k_{i} \pi\left(p_{m}\right)$ for $i \in$ $\{1,2\}$. Hence, for each pair $\left(q_{i}, q_{j}\right) \in[0,1] \times[0,1]$, this sequence converges. Let $v_{i}\left(q_{i}, q_{j}\right)=\lim _{n \rightarrow \infty} v_{i}^{(n+1)}$. One can show that $v_{i}\left(q_{i}, q_{j}\right)$ is continuous and non-increasing in both its arguments.

Now let $\underline{p}_{i}=\phi_{i}^{-1}\left(v_{i}\left(q_{i}, q_{j}\right)\right)$. Since Lemma 6 implies that $\bar{p}_{i}=\min \left\{\underline{p}_{i}+\right.$ $\left.t, p_{m}\right\}$, we can use the convenient notation:

$$
\bar{p}_{i}\left(q_{i}, q_{j}\right)=\min \left\{\phi_{i}^{-1}\left(v_{i}\left(q_{i}, q_{j}\right)\right)+t, p_{m}\right\} .
$$

Since $G_{j}\left(p_{i}+t_{j}\right)=G_{j}\left(\bar{p}_{i}-t_{i}\right), v_{i}\left(q_{i}, q_{j}\right)$ and $v_{j}\left(q_{i}, q_{j}\right)$ are indeed the values of the game as long as $v_{i}\left(q_{i}, q_{j}\right)=q_{j} k_{i} \pi\left(\bar{p}_{i}\left(q_{i}, q_{j}\right)\right)$ and $v_{j}\left(q_{i}, q_{j}\right)=$ $q_{i} k_{j} \pi\left(\bar{p}_{j}\left(q_{i}, q_{j}\right)\right)$. We will now show that such a pair exists.

Since $v_{i}\left(q_{i}, q_{j}\right) \leqslant k_{i} \pi\left(p_{m}\right)$ and $0<\bar{p}_{i}\left(q_{i}, q_{j}\right) \leqslant p_{m}$, we can define a mapping $\Phi:[0,1] \times[0,1] \rightarrow[0,1] \times[0,1]$ whose rule is

$$
\Phi\left(q_{i}, q_{j}\right)=\left[v_{i}\left(q_{i}, q_{j}\right) / k_{i} \pi\left(\bar{p}_{i}\left(q_{i}, q_{j}\right)\right), v_{j}\left(q_{i}, q_{j}\right) / k_{j} \pi\left(\bar{p}_{j}\left(q_{i}, q_{j}\right)\right)\right] .
$$

Because $v_{i}(\cdot, \cdot), \phi_{i}^{-1}(\cdot)$, and $\pi(\cdot)$ are all continuous, so is $\Phi(\cdot, \cdot)$. Since $\Phi(\cdot, \cdot)$ maps $[0,1] \times[0,1]$ into itself, it has a fixed point. Using the 
concavity of $\pi(\cdot)$, it is possible to show that $\Phi(\cdot, \cdot)$ is decreasing in each of its arguments. Hence, this fixed point is unique.

Let $\left(q_{i}, q_{j}\right)$ be the fixed point of $\Phi(\cdot, \cdot)$. We will now show that this fixed point is the equilibrium for the game. A big advantage of the iterative procedure described in (1) is that it gives a method for computing the value of the game for any list of parameters. We can now state our most important result.

Theorem 1. Fix $k_{1}, k_{2}, t_{1}$, and $t_{2}$. Then there is a unique equilibrium.

(a) For small $t \equiv t_{i}+t_{j}$, the equilibrium strategy for firm $i$ is

$$
G_{i}(p)= \begin{cases}1, & \text { if } p<\underline{p}_{i}, \\ v_{j} / k_{j} \pi\left(p+t_{j}\right), & \text { if } \underline{p}_{i} \leqslant p \leqslant \bar{p}_{j}-t_{j}, \\ v_{j} / k_{j} \pi\left(\bar{p}_{j}\right), & \text { if } \bar{p}_{j}-t_{j}<p<\underline{p}_{j}+t_{i}, \\ {\left[v_{j}-k_{j} \pi\left(p-t_{i}\right)\right] / k_{i} \pi_{j}^{*}\left(p-t_{i}\right),} & \text { if } \underline{p}_{j}+t_{i} \leqslant p \leqslant p_{i}, \\ 0, & \text { if } \bar{p}_{i}<p\end{cases}
$$

(b) For large $t_{i}$ and small $t_{j}$, the equilibrium strategies are

$$
\begin{aligned}
& G_{i}(p)= \begin{cases}1, & \text { if } p<p_{i}, \\
v_{j} / k_{j} \pi\left(p+t_{j}\right), & \text { if } \underline{p}_{i} \leqslant p \leqslant p_{m}-t_{j}, \\
v_{j} / k_{j} \pi\left(p_{m}\right), & \text { if } p_{m}-t_{j}<p \leqslant p_{m}, \\
0, & \text { if } p_{m}<p ;\end{cases} \\
& G_{j}(p)= \begin{cases}1, & \text { if } p<p_{i}+t_{j}, \\
{\left[v_{i}-k_{i} \pi\left(p-t_{j}\right)\right] / k_{j} \pi_{i}^{*}\left(p-t_{j}\right),} & \text { if } \underline{p}_{i}+t_{j} \leqslant p_{m} \leqslant p, \\
0, & \text { if } p_{m}<p ;\end{cases}
\end{aligned}
$$

and

(c) For large $t_{i}$ and large $t_{j}$, the equilibrium strategies are

$$
G_{i}(p)=\left\{\begin{array}{ll}
1, & \text { if } p \leqslant p_{m} \\
0, & \text { if } p_{m}<p
\end{array} .\right.
$$

Proof. The existence of the equilibrium follows from a straightforward extension of Theorem 5(b) in Dasgupta and Maskin (1986a). Let

$$
G_{j}\left(\underline{p}_{i}+t_{j}\right)=G_{j}\left(\bar{p}_{i}-t_{i}\right)=q_{j}
$$

where $\left(q_{i}, q_{j}\right)$ is the fixed point of the mapping defined in (2). Then the uniqueness of the pair $\left(v_{1}, v_{2}\right)$ follows from the arguments above showing that $\Phi(\cdot, \cdot)$ has only one fixed point. We will now verify that these strategies do indeed constitute an equilibrium. 
Consider case (a). If $p<p_{j}$, then $G_{i}\left(p+t_{i}\right)>\left[v_{j}-k_{j} \pi(p)\right] / k_{i} \pi_{j}^{*}(p)$, so it pays for firm $j$ to raise its price. If $\underline{p}_{i}<p<\bar{p}_{j}-t_{j}$, then $p+t_{i} \geqslant \bar{p}_{i}$ and $G_{i}\left(p+t_{i}\right)=0$. Hence, if firm $j$ charges $p \in\left[p_{i}, \bar{p}_{j}-t_{j}\right]$, it captures market $j$ and only market $j$ with probability $G_{i}\left(p-t_{j}\right)=v_{j} / k_{j} \pi(p)$, giving expected profits $v_{j}$. If $p \in\left(\bar{p}_{j}-t_{j}, p_{j}+t_{i}\right)$, then $G_{i}\left(p-t_{i}\right)<v_{j} / k_{j} \pi(p)$ and firm $j$ should lower its price; further, $G_{i}\left(p+t_{j}\right)>\left[v_{j}-k_{j} \pi(p)\right] / k_{i} \pi_{j}^{*}(p)$ and firm $j$ should raise its price. If $\underline{p}_{j}+t_{i} \leqslant p \leqslant p_{i}$, then $p-t_{j}<p_{i}$ and $G_{i}\left(p-t_{j}\right)=1$. So if firm $j$ charges $p \in\left[p_{j}+t_{i}, \bar{p}_{i}\right]$, it captures market $j$ with certainty and market $i$ with probability $G_{i}\left(p+t_{i}\right)=\left[v_{j}-k_{j} \pi(p)\right] / k_{i} \pi_{j}^{*}(p)$, again yielding expected profits $v_{j}$. If $p>\bar{p}_{j}$, then $G_{i}\left(p-t_{j}\right)<v_{j} / k_{j} \pi(p)$, so firm $j$ makes higher expected profits by lowering its price.

Consider case (b). The only difference now is that $t_{i}$ is so high that firm $j$ no longer finds it profitable to sell abroad. If firm $i$ charges a price $p<p_{i}$, then $G_{j}\left(p+t_{j}\right)>\left[v_{i}-k_{i} \pi(p)\right] / k_{j} \pi_{i}^{*}(p)$, so it pays for firm $i$ to raise its price. Of course, neither firm charges above $p_{m}$. Also, if firm $j$ charges $p<\underline{p}_{i}+t_{j}$, it wins its own market with certainty but its profit rate is too low. The fact that expected profits are constant on the support of each firm's equilibrium strategy follows as in part (a).

Consider case (c). Both firms charge the monopoly price with positive probability, and neither firm has expected profits in its foreign market.

Theorem 1 establishes the patterns of competition illustrated in Fig. 1. This figure is drawn for two equally sized markets with perfectly inelastic demand where each monopoly price is 5 ; it uses the tariff pairs given in Table 1 below to determine the exact upper and lower bounds of each firm's equilibrium strategies. The bold line segments indicate the support of the firms' equilibrium strategies. Here is how to interpret the figure. Consider the strategy for firm 1 depicted in Fig. 1(a). The arrow from firm 1's support to firm 2's prices indicates that any price $1.41 \leqslant p \leqslant 2.41$ attacks the foreign market at the after-tariff price $p+1$; such a price is aggressive because it captures the home market with certainty and the foreign market with some positive probability. Any price $2.41<p \leqslant 3.41$ is conservative. Also, any price $3.41<p$ loses the domestic market with such high probability that it is not optimal to charge it, while any $p<1.41$ earns too low an expected profit to be optimal. Since $t_{1}=t_{2}=1$, these results are symmetric for firm 2 , and the arrows from firm 2's support to firm 1's prices indicate analogous effects for firm 2.

Part (a) of Theorem 1 corresponds to Fig. 1(a) and Fig. 1(a'). For low tariffs, the strategies have connected supports that are bounded away from the monopoly price. A high tariff gives rise to increased protection of the domestic market and leads to higher profits. Both firms still compete for both markets, but firms charge prices near the monopoly price. Fig. 1( $\left.\mathrm{a}^{\prime}\right)$ represents the case in which $\underline{p}_{i}+t>p_{m}$ and $p_{j}+t>p_{m}$. For firm 1, any price 


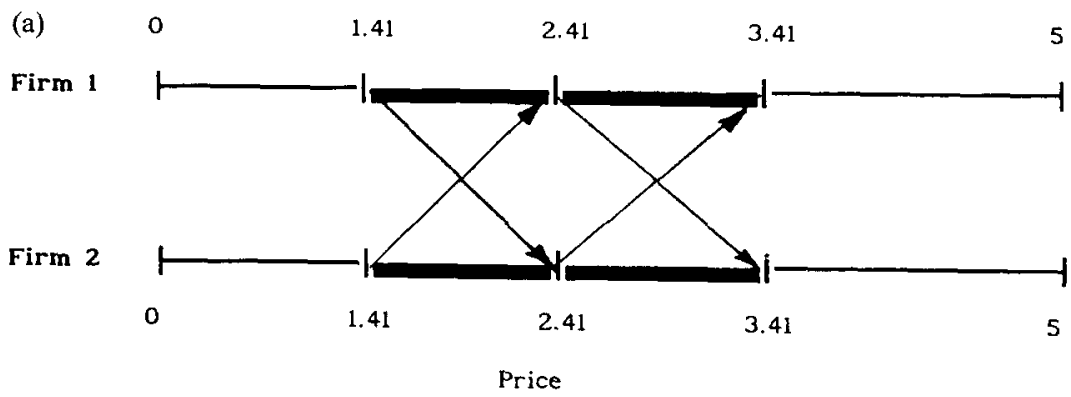
$\left(a^{\prime}\right)$
2.32
3
4.32 5

Firm

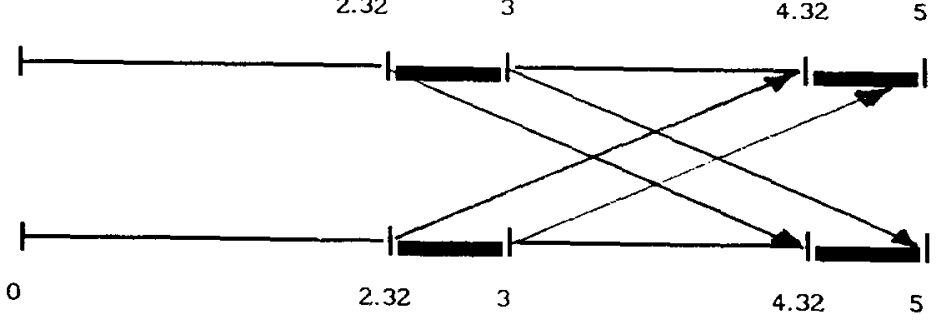

Price

(b)

$2.5 \quad 4 \quad 5$

Firm

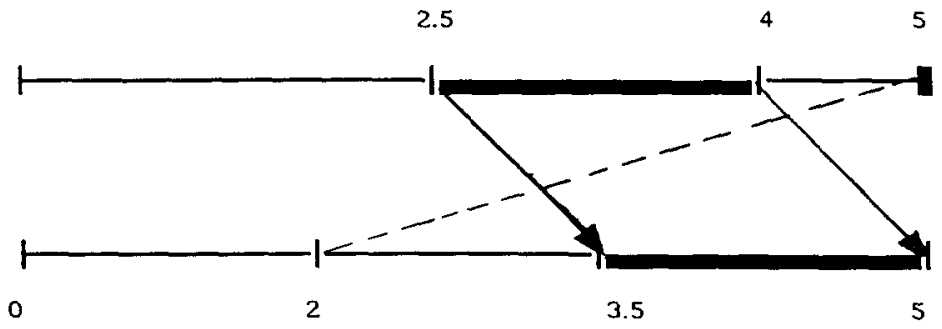

(c)

Price

2

5

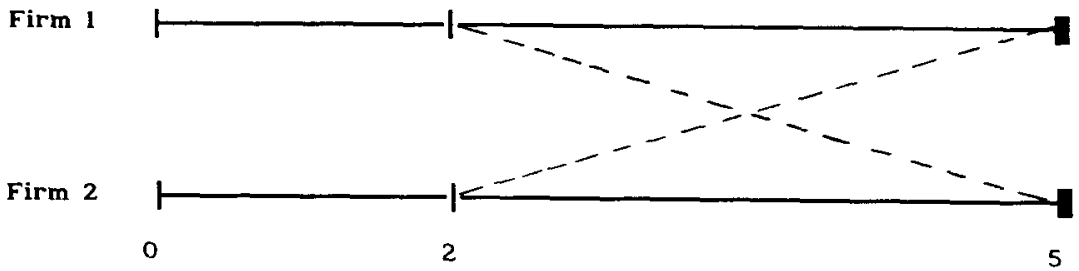

Price

Fig. 1. The supports of the equilibrium strategies. (a) $t_{1}=1$ and $t_{2}=1$; (a') $t_{1}=2$ and $t_{2}=2$; (b) $t_{1}=3$ and $t_{2}=1 ;(c) t_{1}=3$ and $t_{2}=3$. 
Table 1

The relation between profits and tariff rates: $k_{1}=k_{2}=1, p_{m}=5$

\begin{tabular}{llllllll}
\hline$t_{1}$ & $t_{2}$ & $p_{1}$ & $p_{2}$ & $\bar{p}_{1}$ & $\bar{p}_{2}$ & $v_{1}$ & $v_{2}$ \\
\hline 1 & 0 & 0.84 & 0.54 & 1.84 & 1.54 & 1.54 & 0.84 \\
1 & 1 & 1.41 & 1.41 & 3.41 & 3.41 & 2.41 & 2.41 \\
2 & 0 & 1.68 & 1.09 & 3.68 & 3.09 & 3.09 & 1.68 \\
2 & 1 & 2.20 & 1.95 & 5.00 & 4.94 & 3.95 & 3.21 \\
2 & 2 & 2.32 & 2.32 & 5.00 & 5.00 & 4.32 & 4.32 \\
3 & 0 & 2.39 & 1.57 & 5.00 & 4.57 & 4.57 & 2.39 \\
3 & 1 & 2.50 & 3.50 & 5.00 & 5.00 & 5.00 & 3.50 \\
3 & 2 & 2.50 & 4.50 & 5.00 & 5.00 & 5.00 & 4.50 \\
3 & 3 & 5.00 & 5.00 & 5.00 & 5.00 & 5.00 & 5.00 \\
\hline
\end{tabular}

$2.32 \leqslant p \leqslant 3$ is aggressive since there is no chance of imports from firm 2 and there is a positive probability of exporting to the market of firm 2 . On the other hand, any price $4.32 \leqslant p \leqslant 5$ is conservative because firm 1 has no probability of exporting and has a positive probability of suffering from imports into its own market. Again, the interpretation for firm 2 is analogous because the tariffs are symmetric.

Part (b) of Theorem 1 describes the equilibrium when one country imposes a much higher tariff than the other. It corresponds to Fig. 1(b). There is a high tariff in country 1 , and firm 1 captures its own market with certainty even at the monopoly price. However, the domestic market of firm 2 is less protected. Consequently, firm 1 sometimes charges aggressive prices in an attempt to capture both markets. Now, for firm 1 , a price $2.5 \leqslant p \leqslant 4$ is aggressive because these prices attack firm 2's market and represent a positive probability of exports. The broad band at price 5 indicates that firm 1 's equilibrium strategy has a mass point at the monopoly price. For firm 1, charging $p=p_{m}=5$ is conservative because it will not be able to export. For firm 2, a price $3.5 \leqslant p \leqslant 5$ is conservative; in equilibrium, it does not export to firm 1's market because $t_{1}$ is high enough so that undercutting firm 1 is no longer profitable. The dashed line in the figure shows that firm 2 would have to charge such a low price that the forgone expected profits in its own market are not worth the increased expected profits from exporting. This case is, of course, highly asymmetric.

Part (c) of Theorem 1 describes the equilibrium when both countries' tariffs are high enough to segment the markets. It corresponds to Fig. 1(c). Each firm captures its own market at the monopoly price, and tariffs are so high that neither has an incentive to compete for the foreign market, a fact that is illustrated by the two dashed lines in the figure. Now both firms are conservative in fully protected domestic markets. 


\section{Comparative statics}

In this section we examine how equilibrium profits change with the tariffs and the sizes of the markets. We show that an increase in either tariff decreases the profits of neither firm. We conclude by presenting simulations illustrating the comparative statics of the model; these results show that a larger world market may decrease the profits of a protected firm.

Theorem 2. (a) If $t=t_{i}+t_{j}$ is small, then an increase in either tariff increases the equilibrium expected profits of both firms; (b) if $t_{i}$ is large and $t_{j}$ is small, then an increase in $t_{i}$ has no effect on the equilibrium expected profits of firm $j$, although an increase in $t_{j}$ does increase firm $j$ 's expected profits; and (c) if both $t_{i}$ and $t_{j}$ are large, then an increase in either tariff has no effect on either firm's equilibrium expected profits.

Proof. First note that $v_{i}\left(q_{i}, q_{j}\right)$ is differentiable because $\pi(\cdot)$ and hence $\phi_{i}^{-1}(\cdot)$ both are. We will show: (a) $\partial v_{i} / \partial t_{i}$ and $\partial v_{i} / \partial t_{j}>0$ for small $t=t_{i}+t_{j}$; (b) $\partial v_{j} / \partial t_{j}>0$ and $\partial v_{j} / \partial t_{i}=0$ for large $t_{i}$ and small $t_{j}$; and (c) $\partial v_{i} / \partial t_{j}=$ $\partial v_{i} / \partial t_{j}=0$ for large $t_{i}$ and large $t_{j}$. Note that cases (a), (b), and (c) of Theorem 2 correspond to the analogous cases of Theorem 1.

Consider case (a) of Theorem 1 , and recall the definition of $p_{i}^{(n+1)}$ given in Eq. (1). Since $t_{i}+t_{j}$ is small, it follows that $p_{i}^{(n+1)}$ is increasing in $t_{i}$ as long as $p_{i}^{(n+1)}<p_{m}$. Hence each $v_{i}^{(n+1)}$ is increasing in $t_{i}$, and the limiting value of that sequence is also increasing in $t_{i}$. Likewise, $v_{j}^{(n+1)}$ is increasing in $t_{j}$. But then so is $p_{i}^{(n+1)}=\min \left\{\phi_{j}^{-1}\left(v_{j}^{(n)}\right)+t_{i}\right\}$. Since $v_{i}^{(n+1)}=k_{i} \pi\left(p_{i}^{(n+1)}\right)$, the limiting value of this sequence is also increasing in $t_{j}$.

Consider case (b) of Theorem 1. Then $k_{i} \pi\left(p_{m}\right)=k_{i} \pi\left(p_{i}\right)+k_{j} \pi_{i}^{*}\left(\underline{p}_{i}\right)$. This expression is independent of $t_{i}$, and it implies that $p_{i}$ does not depend on $t_{i}$. Since $v_{j}=k_{j} \pi\left(p_{i}+t_{j}\right), v_{j}$ is also independent of $t_{i}$. However, since $\pi(\cdot)$ is increasing, $\partial v_{j} / \partial t_{j}>0$ as long as $v_{j}<k_{j} \pi\left(p_{m}\right)$.

Consider case (c) of Theorem 1. Small changes in $t_{i}$ and $t_{j}$ have no effect on the equilibrium strategies.

Case (a) of Theorem 2 shows that an increased domestic tariff benefits the domestic firm because it increases the chance that the home-country firm captures its own market. Because of the increased protection, the domestic firm becomes less aggressive, reducing the competitive pressure on the foreign firm. Consequently, an increase in the home-country tariff also benefits the foreign firm, as long as the foreign firm has some probability of exporting to the protected domestic market. Case (b) shows that if a high home-country tariff perfectly protects the domestic market in equilibrium, then any further increase of the home-country tariff will not benefit the 
foreign firm, although an increase in the foreign tariff may raise its expected profits. Case (c) states that the tariffs eventually become so high that they segment the two markets; any further increase has no effect on either firm.

Table 1 illustrates how the equilibrium is affected by the two tariffs, again for the case of perfectly inelastic demand and symmetric markets. Lemma 6 implied that $\bar{p}_{i}=p_{i}+t$ whenever $\bar{p}_{i}<p_{m}$. Therefore, at price $p_{j}-t_{j}$ firm $i$ just captures its own market but never the foreign market, resulting in an equilibrium profit of $k_{i}\left(\vec{p}_{j}-t_{j}\right)$. The table is also consistent with Theorem 2, which states that an increase in one tariff always increases the profits of both firms unless the monopoly profit has been reached. In fact the profits of the domestic firm generally rise more than proportionately with the tariffs. This occurs because each firm is less aggressive and profits are a linear function of price in this example. Fig. 1 above is drawn from the data in Table 1.

Table 2 illustrates how the profits change as the size of the market in country 2 changes. We assume equal tariffs now, but the per capita demands are as before. Notice that firm 2 always benefits from an increase in the size of its own market. However, the profits to firm 1 begin to fall with an increase in the size of its foreign market. This drop reflects the increased competition for the larger market. A firm can always guarantee itself the profits from selling at the tariff in its own market; hence, an increase in the size of its own domestic market raises a firm's equilibrium profits. But a firm whose export market is disproportionately large will become aggressive; hence, the other firm must charge conservative prices to protect its own large market. Then the aggressive firm's prices fall and so do its equilibrium profits.

The limiting cases illustrate these ideas forcefully. Let the population $k_{1}=1$ and let $k_{2}$, the number of consumers in the second market, converge

Table 2

The relation between profits and relative market size: $k_{1}=1, t_{1}=t_{2}=1, p_{m}=5$

\begin{tabular}{rlllr}
\hline$k_{2}$ & $\bar{p}_{1}$ & $\bar{p}_{2}$ & $v_{1}$ & $v_{2}$ \\
\hline 0.09 & 3.14 & 2.17 & 1.17 & 0.19 \\
0.49 & 3.51 & 2.90 & 1.90 & 1.22 \\
0.81 & 3.50 & 3.29 & 2.29 & 2.01 \\
1.00 & 3.41 & 3.41 & 2.41 & 2.41 \\
1.15 & 3.33 & 3.48 & 2.47 & 2.69 \\
1.24 & 3.29 & 3.50 & 2.50 & 2.83 \\
1.38 & 3.21 & 3.52 & 2.52 & 3.05 \\
1.62 & 3.09 & 3.53 & 2.53 & 3.38 \\
2.06 & 2.90 & 3.51 & 2.51 & 3.92 \\
2.96 & 2.65 & 3.42 & 2.42 & 4.90 \\
5.10 & 2.39 & 3.28 & 2.28 & 7.08 \\
11.50 & 2.17 & 3.14 & 2.14 & 13.50 \\
\hline
\end{tabular}


to zero. ${ }^{6}$ Then, applying the algorithm in (1), we see that $\lim _{k_{2} \rightarrow 0} v_{1}=t_{1}$ and $\lim _{k_{2} \rightarrow 0} v_{2}=0$. Also, the equilibrium strategies satisfy $\lim _{k_{2} \rightarrow 0} p_{1}=t_{1}$, $\lim _{k_{2} \rightarrow 0} \bar{p}_{1}=\min \left\{t_{1}+t, p_{m}\right\}, \lim _{k_{2} \rightarrow 0} \underline{p}_{2}=0$, and $\lim _{k_{2} \rightarrow 0} \bar{p}_{2}=\min \left\{t, p_{m}\right\}$. Hence, firm 2's most aggressive strategy approaches pricing at marginal cost as its own market shrinks; firm 1's most aggressive strategy becomes charging the tariff rate in its own market.

Now let $k_{1}=1$ and $k_{2}$ be large. Then $v_{2}$ will also be large, and firm 2 will charge prices no greater than $t_{2}$ with arbitrarily high probability. Since the highest price firm 2 will charge is near $t_{2}$, in equilibrium, firm 1 can earn approximate expected profits $t=t_{1}+t_{2}$ by charging a conservative price in near $t$. Firm 1 need not fear that firm 2 will lower its price because gains from sales in firm 1's small market do not offset lost revenues from sales in firm 2's large home market. These two examples illustrate precisely what it means to be a small country in this model; a large-country firm worries about losing its domestic market and charges its own tariff with high probability. The small-county firm takes the world price as given and occasionally reaps rents in its own (doubly protected) domestic market.

Table 2 shows numerically how the shift in the pattern of competition is related to the difference between $\bar{p}_{1}$ and $\bar{p}_{2}$. If country 2 is small, this difference is nearly equal to the tariff, and firm 2 tries to capture the larger foreign market. On the other hand, if country 2 is large, the relation between $\bar{p}_{1}$ and $\bar{p}_{2}$ is essentially reversed. Now both firms compete for the domestic market of firm 2 . Firm 1 becomes more aggressive, and firm 2 is conservative, accruing high profit rates in a large domestic market. ${ }^{8}$

\section{Conclusion}

We have analyzed a model of price-setting duopoly in which each firm may be subject to a tariff. If dumping is prohibited, the imposition of a tariff

\footnotetext{
${ }^{6}$ We need to consider a sequence of such markets because $\phi_{1}^{-1}(\cdot)$ is not single-valued if $k_{2}=0$.

${ }^{7}$ Theorem 1 implies that no firm $i$ has expected equilibrium profits greater than $\Pi_{i}\left(p, G_{j}\right)=$ $k_{i} \pi\left(p_{m}\right)$, the expected profits in a perfectly protected domestic market. Hence, although $k_{2}$ and $v_{2}$ are arbitrarily large, $v_{1}$ is bounded. Now let $\varepsilon>0$, and assume that $G_{2}\left(t_{2}+\varepsilon\right)>0$. Then firm 1 can charge $p=\varepsilon$, earning arbitrarily large expected profits. This contradiction establishes that firm 2 almost surely charges prices no greater than $t_{2}$.

${ }^{8}$ The astute reader might ask why the values in Table 2 are not symmetric, in the sense that $\left(v_{1} / k_{1}\right) /\left(v_{2} / k_{2}\right)$ be a constant. Because $t_{1}=t_{2}=1$ and demand is perfectly inelastic in both markets. Theorem 1 implies that $v_{1}=p_{2}+1$ and $v_{2}=k_{2}\left(p_{1}+1\right)$. Hence, $v_{1} / v_{2}=\left(1 / k_{2}\right)\left(p_{2}+\right.$ $1) /\left(p_{1}+1\right)$. As $k_{2}$ grows large, firm 2 's most aggressive strategy rises to $t_{2}$, while firm 1 's most aggressive strategy becomes arbitrarily near zero. Hence, $\left(v_{1} / k_{1}\right) /\left(v_{2} / k_{2}\right)=\left(p_{2}+1\right) /\left(p_{1}+1\right)$ increases. Of course, this result depends upon the functional form assumed for demand in each market.
} 
in one market influences the strategies of both firms in both markets. Although price setting by two firms producing a homogeneous good is a simple model of imperfect competition, introducing tariffs has quite complex effects. Moreover, these effects cannot be captured by a model with differentiated goods because such an analysis allows implicitly for market segmentation. It is surprising that our simple model has so complex a solution, but the interpretation of the equilibrium strategies as mixtures of conservative and aggressive marketing policies is compelling.

This analysis showed that commercial policy in oligopolistic markets may have unexpected effects. In particular, to the extent that producers make strategic choices involving sales in international markets, the imposition of a trade restriction aimed at one firm in one market influences the choices of all firms in all markets. Tariffs do not have to be as large as the monopoly price to be prohibitive. Also, when one firm has a perfectly protected market, a marginal change in the commercial policy of its trading partner has no effect on the protected firm's expected profits. Finally, an exogenous increase in the size of one's export market may have beneficial effects on domestic consumers because it induces a domestic firm to be more aggressive in the face of a foreign tariff.

\section{Acknowledgements}

The authors thank two anonymous referees, an editor, Dan Kovenock, Sally Davies, and Ralph Tryon for helpful comments on earlier drafts of this paper. Fisher benefited from time at the Stockholm University's Institute for International Economics and the Tinbergen Institute at Rotterdam. Wilson acknowledges support from the Institute for Advanced Studies at the Hebrew University in Jerusalem, the Alfred P. Sloan Foundation, and the C.V. Starr Center for Applied Economics.

\section{Appendix}

\section{Proof of Lemma 2}

Suppose $q_{i}(p)>0$. Then there is a $\delta>0$ such that $G_{i}\left(p-t_{i}+\delta\right)=$ $G_{i}\left(p-t_{j}\right)$ and $G_{i}\left(p+t_{i}+\delta\right)=G_{i}\left(p+t_{i}\right)$. Since Lemma 1 implies that $v_{j}>0$, it follows that $G_{i}\left(p-t_{j}\right)>0$. Further, if $p<p_{m}-t_{i}$, then Assumption 1 implies that both $\pi(p)$ and $\pi_{i}^{*}(p)$ are increasing. If $p \in\left[p_{m}-t_{i}, p_{m}\right], \pi(p)$ is still increasing, but $G_{i}\left(p+t_{i}+\delta\right)=0$ so firm $j$ never captures market $i$. Therefore, unless $p=p_{m}$, there is $\delta>0$ such that the expect profits of firm $j$ are higher at $p+\delta$ then at $p$. 


\section{Proof of Lemma 3}

(a) Suppose $G_{i}\left(\bar{p}_{i}-t_{i}\right)=0$. Then at $p$ near $\bar{p}_{i}$, the expected profits of firm $i$ are near zero, contradicting Lemma 1 .

(b) At any $p>\bar{p}_{i}+t_{j}$, the expected profits of firm $j$ are zero. Further, if $q_{i}\left(\bar{p}_{i}\right)>0$, then firm $j$ can increase profits by charging a price just below $\bar{p}_{i}+t_{i}$.

(c) The first inequality follows from (a). We establish the second inequality by reversing subscripts in (b) and noting that firm $j$ never captures market $i$ at price $\bar{p}_{i}$ or higher. Any increase in price lowers the probability that firm $j$ captures its own market. Since profits per customer are maximized at $p_{m}$, the result follows.

(d) At any $p<\underline{p}_{i}-t_{i}$, firm $j$ captures both markets with certainty. Since profits are increasing in both markets for $p<p_{m}-t_{i}$, firm $j$ never charges price below $\underline{p}_{i}-t_{i}$.

\section{Proof of Lemma 4}

Lemma 3(b) implies that if firm $i$ charges $\bar{p}_{i}$, it never captures market $j$. Now suppose firm $i$ charges $p$ just under $\bar{p}_{i}-t$. Then it captures market $j$ with the same probability that it would capture market $i$ at $\bar{p}_{i}$ and the probability that it captures its home market increases. Since $D(p)$ is decreasing, firm $i$ 's expected sales increase by at least a factor of $\left(k_{1}+k_{2}\right) /$ $k_{i}$. Hence, it is profitable to charge $\bar{p}_{i}$ only if $k_{i} \bar{p}_{i} \geqslant\left(k_{1}+k_{2}\right)\left(\bar{p}_{i}-t\right)$.

\section{Proof of Lemma 5}

We establish the lemma in a series of steps. Let $\Pi_{i}^{\mathrm{d}}\left(p, G_{j}\right)=k_{i} G_{j}(p-$ $\left.t_{i}\right) \pi(p)$ be firm $i$ 's expected profit from domestic sales and $\Pi_{i}^{\mathrm{f}}\left(p, G_{j}\right)=$ $k_{j} G_{j}\left(p+t_{j}\right) \pi_{i}^{*}(p)$ be analogous for foreign sales.

Step 1. Suppose $p^{\prime} \leqslant p^{\prime \prime} \leqslant p_{m}-t$. Then $\Pi_{i}^{d}\left(p^{\prime \prime}+t, G_{j}\right) \geqslant \Pi_{i}^{d}\left(p^{\prime}+t, G_{j}\right)>0$ implies $\Pi_{i}^{f}\left(p^{\prime \prime}, G_{j}\right)>\Pi_{i}^{f}\left(p^{\prime}, G_{j}\right)$.

Proof. Suppose $\Pi_{i}^{\mathrm{d}}\left(p^{\prime \prime}+t, G_{j}\right) \geqslant \Pi_{i}^{\mathrm{d}}\left(p^{\prime}+t, G_{j}\right)>0$. Then $G_{i}\left(p^{\prime \prime}+t_{j}\right) \pi\left(p^{\prime \prime}+\right.$ $t) \geqslant G_{j}\left(p^{\prime}+t_{j}\right) \pi\left(p^{\prime}+t\right)>0$. Then Assumption 1 implies that

$$
\begin{gathered}
G_{j}\left(p^{\prime \prime}+t_{j}\right) / G_{j}\left(p^{\prime}+t_{j}\right) \geqslant \pi\left(p^{\prime}+t\right) / \pi\left(p^{\prime \prime}+t\right) \geqslant \pi\left(p^{\prime}+t_{j}\right) / \pi\left(p^{\prime \prime}+t_{j}\right) \\
=\left[\left(p^{\prime}+t_{j}\right) \pi_{i}^{*}\left(p^{\prime}\right) / p^{\prime}\right] /\left[\left(p^{\prime \prime}+t_{j}\right) \pi_{i}^{*}\left(p^{\prime \prime}\right) / p^{\prime \prime}\right] \geqslant \pi_{i}^{*}\left(p^{\prime}\right) / \pi_{i}^{*}\left(p^{\prime \prime}\right),
\end{gathered}
$$

where the second inequality is strict if $t_{i}>0$ and the last inequality is strict if $t_{j}>0$. Since $t=t_{i}+t_{j}>0$, the result follows.

Step 2. If $\underline{p}_{i}+t<\bar{p}_{i}$, then $\underline{p}_{j}+t<\bar{p}-t_{i} \leqslant \bar{p}_{j}$ and $\underline{p}_{i}+t<\bar{p}-t_{j} \leqslant \bar{p}_{i}$.

Proof. Since $v_{i}=\Pi_{i}\left(\bar{p}_{i}, G_{j}\right)$, it follows that 


$$
\begin{aligned}
0 \leqslant & \Pi_{i}\left(\bar{p}_{i}, G_{j}\right)-\Pi_{i}\left(\underline{p}_{i}+t, G_{j}\right) \\
= & {\left[\Pi_{i}^{\mathrm{d}}\left(\bar{p}_{i}, G_{j}\right)-\Pi_{i}^{\mathrm{d}}\left(\underline{p}_{i}+t, G_{j}\right)\right] } \\
& +k_{j}\left[G_{j}\left(\bar{p}_{i}+t_{j}\right) \pi_{i}^{*}\left(\bar{p}_{i}\right)-G_{j}\left(\underline{p}_{i}+t+t_{j}\right) \pi_{i}^{*}\left(\underline{p}_{i}+t\right)\right] .
\end{aligned}
$$

Since Lemma 3(b) implies that $G_{j}\left(\bar{p}_{i}+t_{j}\right)=0$, it follows that $\Pi_{i}^{\mathrm{d}}\left(\bar{p}_{i}, G_{j}\right)-$ $\Pi_{i}^{\mathrm{d}}\left(\underline{p}_{i}+t, G_{j}\right) \geqslant 0$. Because $0<p_{i} \leqslant \bar{p}_{i}$ and Lemma 3(c) implies that $\bar{p}_{i}-t \leqslant$ $p_{m}-t$, it follows from Step 1 that $\Pi_{i}^{\mathrm{i}}\left(\bar{p}_{i}-t, G_{j}\right)>\Pi_{i}^{\mathrm{f}}\left(p_{i}, G_{j}\right)$. Then

$$
\begin{aligned}
0 & \geqslant \Pi_{i}\left(\bar{p}_{i}-t, G_{j}\right)-\Pi_{i}\left(\underline{p}_{i}, G_{j}\right) \geqslant \Pi_{i}^{\mathrm{d}}\left(\bar{p}_{i}-t, G_{j}\right)-\Pi_{i}^{\mathrm{d}}\left(\underline{p}_{i}, G_{j}\right) \\
& =k_{i}\left[G_{j}\left(\bar{p}_{i}-t-t_{i}\right) \pi\left(\bar{p}_{i}-t\right)-G_{j}\left(\underline{p}_{i}-t_{i}\right) \pi\left(\underline{p}_{i}\right)\right] .
\end{aligned}
$$

Since $\bar{p}_{i}-t>p_{i}$, Assumption 1 implies that $G_{j}\left(\bar{p}_{i}-t-t_{i}\right)<1$. Hence, $\underline{p}_{j}+$ $t<\bar{p}_{i}-t_{i}$. Lemma 3(c) implies that $\bar{p}_{i}-t_{i} \leqslant \bar{p}_{j}$. Since the label $i$ was arbitrary, the conclusion that $\underline{p}_{j}+t<\bar{p}_{j}$ immediately implies that $p_{i}+t<$ $\bar{p}-t_{j} \leqslant \bar{p}_{i}$.

Step 3. If $p_{i}+t<\bar{p}_{i}$, then $G_{i}\left(\bar{p}_{j}-t_{j}\right) \leqslant G_{i}\left(p_{j}+t+t_{i}\right)$ and $G_{j}\left(\bar{p}_{i}-t_{i}\right) \leqslant$ $G_{j}\left(\underline{p}_{i}+t+t_{j}\right)$.

Proof. The result is immediate if $\bar{p}_{i}-t_{j} \geqslant p_{j}+t+t_{i}$. So let $p \in\left(\bar{p}_{j}-t-\right.$ $t_{j}, \underline{p}_{j}+t_{i}$ ). Note that Step 2 implies that $p>\underline{p}_{i}$. Since $\underline{p}_{i}$ is in the support of $G_{i}$,

$$
\begin{aligned}
0 & \geqslant \Pi_{i}\left(p, G_{j}\right)-\Pi_{i}\left(p_{i}, G_{j}\right) \\
& =\left[\Pi_{i}^{\mathrm{d}}\left(p, G_{j}\right)-\Pi_{i}^{\mathrm{d}}\left(\underline{p}_{i}, G_{j}\right)\right]+\left[\Pi_{i}^{\mathrm{f}}\left(p, G_{j}\right)-\Pi_{i}^{\mathrm{f}}\left(\underline{p}_{i}, G_{j}\right)\right] \\
& =k_{i}\left[\pi(p)-\pi\left(\underline{p}_{i}\right)\right]+\Pi_{i}^{\mathrm{f}}\left(p, G_{j}\right)-\Pi_{i}^{\mathrm{f}}\left(\underline{p}_{i}, G_{j}\right) \\
& >\Pi_{i}^{\mathrm{f}}\left(p, G_{j}\right)-\Pi_{i}^{\mathrm{f}}\left(\underline{p}_{i}, G_{j}\right),
\end{aligned}
$$

where we have used Assumption 1. Note that $p<\underline{p}_{j}+t_{i} \leqslant \underline{p}_{i}-t \leqslant p_{m}-t$, where the second inequality follows from Step 2 and the third from Lemma 3(c). Then

$$
\begin{aligned}
& \Pi_{i}\left(p+t, G_{j}\right)-\Pi_{i}\left(p_{i}+t, G_{j}\right) \\
& \quad=\left[\Pi_{i}^{\mathrm{d}}\left(p+t, G_{j}\right)-\Pi_{i}^{\mathrm{d}}\left(p_{i}+t, G_{j}\right)\right]+\left[\Pi_{i}^{\mathrm{f}}\left(p+t, G_{j}\right)-\Pi_{i}^{\mathrm{f}}\left(\underline{p}_{i}+t, G_{j}\right)\right] \\
& \left.\quad<\Pi_{i}^{\mathrm{f}}\left(p+t, G_{j}\right)-\Pi_{i}^{\mathrm{f}}\left(\underline{p}_{i}+t, G_{j}\right)\right] \\
& \quad=k_{j}\left[G_{j}\left(p+t+t_{j}\right) \pi_{i}^{*}(p+t)-G_{j}\left(\underline{p}_{i}+t+t_{j}\right) \pi_{i}^{*}\left(\underline{p}_{i}+t\right)\right],
\end{aligned}
$$

where the inequality follows from the contrapositive of Step 1. But $p+t+$ $t_{j}>\bar{p}_{j}$ implies that $G_{i}\left(p+t+t_{j}\right)=0$ and hence $\Pi_{i}\left(p+t, G_{i}\right)<\Pi_{i}\left(p_{i}+\right.$ $\left.t, G_{j}\right)$. Hence, it is not optimal for $i$ to charge $p \in\left(\bar{p}_{j}-t_{j}, \underline{p}_{j}+t+t_{i}\right)$. Then the result follows from Lemma 3 and the fact that the label $i$ was arbitrary. 
Step 4. If $\underline{p}_{i}+t<\bar{p}_{i}$, then $\bar{p}_{i} \geqslant \min \left\{p_{m}, \underline{p}_{i}+2 t\right\}$.

Proof. The result is immediate if $\bar{p}_{i} \geqslant p_{i}+2 t$. So let $p \in\left(\bar{p}_{i}, \underline{p}_{i}+2 t\right)$. Since Lemma 3(b) implies $G_{j}\left(\bar{p}_{i}+t_{j}\right)=0$, it follows that

$$
0 \geqslant \Pi_{i}\left(p, G_{j}\right)-\Pi_{i}\left(\bar{p}_{i}, G_{j}\right)=k_{i}\left[G_{j}\left(p-t_{j}\right) \pi(p)-G_{j}\left(\bar{p}_{i}-t_{j}\right) \pi\left(\vec{p}_{i}\right)\right] .
$$

Lemma 3(a) and Step 3 imply that $0<G_{j}\left(\bar{p}_{i}-t_{i}\right) \leqslant G_{j}\left(p_{i}+t+t_{j}\right) \leqslant G_{j}(p-$ $\left.t_{i}\right)$, where the last inequality is true because $p<p_{i}+2 t$. Hence, $\pi(p) \leqslant$ $\pi\left(\bar{p}_{i}\right)$. But Assumption 1 then implies that $\bar{p}_{i}=p_{m}$.

Step 5. If $\underline{p}_{i}+t<\bar{p}_{i}$, then $\bar{p}_{1}=\bar{p}_{2}=p_{m}$.

Proof. If $\underline{p}_{i}+t<\bar{p}_{i}$, then Step 2 implies that $\underline{p}_{j}+t<\bar{p}_{j}$. Lemma 4 implies that $\bar{p}_{k} \leqslant 2 t$ for some firm $k$. Then Step 4 implies that $p_{m} \leqslant 2 t$. But then Step 4 implies that $\vec{p}_{i}=p_{m}$.

Step 6. If $\underline{p}_{i}+t<\bar{p}_{i}$, then $\left(k_{i}+k_{j}\right) t \leqslant k_{i} \bar{p}_{i}$.

Proof. Note that

$$
\begin{aligned}
0 \leqslant & \Pi_{i}\left(\bar{p}_{i}, G_{j}\right)-\Pi_{i}\left(\underline{p}_{i}+t, G_{j}\right) \\
= & k_{i}\left[G_{j}\left(\bar{p}_{i}-t_{i}\right) \pi\left(\bar{p}_{i}\right)-G_{j}\left(\underline{p}_{i}+t-t_{i}\right) \pi\left(\underline{p}_{i}+t\right)\right] \\
& +k_{j}\left[G_{j}\left(\bar{p}_{i}+t_{j}\right) \pi_{i}^{*}\left(\bar{p}_{i}\right)-G_{j}\left(\underline{p}_{i}+t+t_{j}\right) \pi_{i}^{*}\left(\underline{p}_{i}+t\right)\right] .
\end{aligned}
$$

Lemma 3 implies that $G_{j}\left(\bar{p}_{i}+t_{j}\right)=0$ and that $G_{j}\left(\bar{p}_{i}-t_{i}\right)>0$, and Step 3 implies that $G_{i}\left(\bar{p}_{i}-t_{i}\right) \leqslant G_{i}\left(p_{i}+t+t_{j}\right)$. Since $\underline{p}_{i}+t<\bar{p}_{i}$ and $G(\cdot)$ does not increase, $G_{j}\left(\bar{p}_{i}-t_{i}\right) \leqslant G_{j}\left(\underline{p}_{i}+t-t_{i}\right)$. Therefore, $k_{i} \pi\left(\bar{p}_{i}\right) \geqslant k_{i} \pi\left(\underline{p}_{i}+t\right)+$ $k_{i} \pi_{i}^{*}\left(\underline{p}_{i}+t\right)$, which is equivalent to $k_{i} \bar{p}_{i} D\left(\bar{p}_{i}\right) \geqslant k_{i}\left(\underline{p}_{i}+t\right)\left[D\left(\underline{p}_{i}+t\right)+\right.$ $\left.k_{j} D\left(\underline{p}_{i}+t+t_{j}\right)\right]$. Steps 2 and 5 imply that $\underline{p}_{i}+t+t_{j} \leqslant \bar{p}_{i}=\bar{p}_{j}=p_{m}$, and Assumption 1 entails that $D(p)$ is not increasing. Hence, $k_{i} \bar{p}_{i} \geqslant\left(k_{1}+\right.$ $\left.k_{2}\right)\left(\underline{p}_{i}+t\right)$. Since Lemma 1 implies that $\underline{p}_{i}>0$, Lemma 5 follows.

Proof of Lemma 6. Since $\underline{p}_{i} \geqslant \bar{p}_{i}-t$, Lemma 3(c) implies that $\bar{p}_{i} \leqslant \min \left\{\underline{p}_{i}+\right.$ $\left.t, p_{m}\right\}$. Suppose that strict inequality holds. Choose $p \in\left(\bar{p}_{i}-t_{i}, \min \left\{\underline{p}_{i}+\right.\right.$ $\left.\left.t_{j}, p_{m}-t_{i}\right\}\right)$. Firm $j$ earns higher profits at $p$ than at any price in the interval $\left(\bar{p}_{i}-t_{i}, p\right)$ because it captures market $j$ with certainty and it never captures market $i$. So firm $j$ never charges a price in $\left(\bar{p}_{i}-t_{i}, p\right)$. But then firm $i$ earns higher profits at $p+t_{j}$ than at $\bar{p}_{i}$ because Lemma 3(b) implies that it never captures market $j$, while the probability that it captures market $i$ remains unchanged. This argument contradicts the definition of $\bar{p}_{i}$. 


\section{References}

Baye, M.R. and C. de Vries, 1992, Mixed strategy trade equilibria, Canadian Journal of Economics 25, 281-293.

Brander, J.A., 1981, Intra-industry trade in identical commodities, Journal of International Economics 11, 1-14.

Bulow, J.I., J.D. Geanakoplos and P.D. Klemperer, 1985, Multi-market oligopoly: Strategic substitutes and complements, Journal of Political Economy 93, 488-511.

Dasgupta, P. and E. Maskin, 1986a, The existence of equilibria in discontinuous games, II: Theory, The Review of Economic Studies LIII, 1-26.

Dasgupta, P. and E. Maskin, 1986b, The existence of equilibria in discontinuous games, I: Applications, The Review of Economic Studies LIII, 27-42.

Eaton, J. and M. Engers, 1990, International price competition, Econometrica 58, 637-660.

Farrell, J. and K. Shapiro, 1988, Dynamic competition with switching costs, Rand Journal of Economics 19, 123-137.

Helpman, E., 1984, Increasing returns, imperfect markets, and trade theory, in: R.W. Jones and P.B. Kenen, eds., Handbook of International Economics: Volume 1, Chapter 7 (North-Holland, Amsterdam).

Krishna, K., 1989, Trade restrictions as facilitating practices, Journal of International Economics 26, 251-270.

Levitan, R.E. and M. Shubik, 1972, Price duopoly and capacity constraints, International Economic Review 13, 111-122.

McMillan, J., 1986, Game theory in international economics (Harwood Academic Publishers, Chur, Switzerland).

Narasimhan, C., 1988, Competitive promotional strategies, Journal of Business 61, 427-449.

Raju, J.S., V. Srinivasan and R. Lal, 1990, The effects of brand loyalty on competitive price promotional strategies, Management Science 36, 276-304.

Shilony, Y., 1977, Mixed pricing in oligopoly, Journal of Economic Theory 14, 373-388.

United States Congress, 1979, Public Law 96-39, Trade Agreements Act, Ninety-sixth Congress.

Varian, H.R., 1980, A model of sales, American Economic Review 70, 561-569. 